\title{
EAl Endorsed Transactions

\section{Engaging Our School Teachers: an Augmented Reality (AR) Approach to Continuous Professional Development}

\author{
Debbie Holley ${ }^{1, *}$ and Philip Howlett ${ }^{2}$ \\ ${ }^{1}$ Executive Business Centre, Bournemouth University, 89 Holdenhurst Road, Bournemouth, BH8 8EB, United Kingdom \\ ${ }^{2}$ Department of Education, Faculty of Health, Social Care and Education, Anglia Ruskin University, Bishop Hall Lane, \\ Chelmsford, CM1 7AY, United Kingdom
}

\section{Abstract}

Currently, teachers in the UK learn about behaviour management strategies from theoretical perspectives when training, through discussions with mentors, and by trial and error at their schools. Existing literature mainly focuses on such issues from the 'adult' viewpoint, not the voice of the child. This paper reports on work-in-progress developing a range of Augmented Reality (AR) resources for these issues, drawing upon co-design research workshops with children from a Year 6 class (aged 10) in a UK Primary School. Our research informs approaches to classroom management by encouraging reflection and analysis of 'critical incidents' identified by the pupils, and explored by teachers in workshops through the medium of AR, giving a reality previously uncaptured in more traditional approaches. Our final resources will be a set of Open Education Resources (OER), offered to the wider community for reuse/repurposing for educational settings through a Creative Commons (cc) licence.

Keywords: Augmented Reality, Classroom behaviour, Co-design, Participative research, OER.

Received on 29 November, 2015, accepted on 01 April, 2016, published on 11 April, 2016

Copyright $\odot 2016$ D. Holley and P. Howlett, licensed to EAI. This is an open access article distributed under the terms of the Creative Commons Attribution licence (http://creativecommons.org/licenses/by/3.0/), which permits unlimited use, distribution and reproduction in any medium so long as the original work is properly cited.

doi: 10.4108/eai.11-4-2016.151150

\section{Introduction}

Currently, trainee teachers in UK school placement/working settings learn about behaviour management strategies from a theoretical perspective at University and through discussions with their school mentors; however, they learn most by trial and error at their placement setting. Qualified part-time and full-time teachers also have to develop their skills in behaviour management mostly by trial and error, and occasionally by specialist training. Haydn [1] emphasises the importance of reading and talking about managing classrooms with a range of practitioners from other schools as it provides the opportunity to explore and discover new ideas which they had not come across before. Our project is seeking to bridge the gap between training and real school settings

*Corresponding author. dholley@bournemouth.ac.uk through the use of 'critical incidents' identified by school pupils, by the medium of Augmented Reality (AR). Our AR materials capture a range 'voices' in the classroom to provide discussion points, such as the children themselves, who have written, designed and acted out scenarios to be filmed for this project, but also those supporting the classroom - the head teacher provides a rationale for the school behaviour policy; the classroom teacher offers his perspective; a newly qualified teacher talks about her fears; an Ofsted inspector talks about the framework for national policy; school governors offer their views, as well as the university lecturers giving an overview of key behaviour theories. Thus a rich and critical learning experience is being developed that can be accessed through face-to-face workshops, but additionally in a fully online context.

Augmented Reality is identified as a key emergent technology in the NMC Horizon Higher Education Preview [2], and the pedagogic context of its use as an 
education tool is the focus of research by assessment expert Bloxham [3]. The increased use of Smartphones, individual devices for accessing the internet is rapidly increasing - in 2012, over 40 million subscribers accessed the internet via their mobile phones, an increase of nearly 9 million since 2011[4]. Just $39 \%$ of high school students said that their school is currently meeting their technology needs according to the 21st Century Classroom Report [5]. It is evident that students at university are now expecting academic staff to lead in the use of educational technology for their learning [6]. Thus, the increasing coverage and use of Bring Your Own Device (BYOD) makes it feasible to implement AR in different learning contexts, and Fink [7] suggests sufficient students now have access to mobile devices with features that enable them to make the most of these materials. Although utilising sophisticated technology, the tools and development environment are now accessible to non-experts (e.g. Vuforia [8]; Aurasma [9]). So, as well as integrating AR resources into the curriculum it is possible for students and staff to create their own artefacts in a constructive learning context. Our materials are hosted through Aurasma, "the world's leading augmented reality platform. Available as a free app for iPhones, iPads and high-powered Android devices or as a kernel for developers, Aurasma uses advanced image and pattern recognition to blend the real-world with rich interactive content such as videos and animations called 'Auras"'[9].

\section{Schools in the United Kingdom: complex policies and options}

Education in the United Kingdom is a complex affair as there are different approaches to the education systems and policies of England, Scotland, Wales and Northern Ireland. Though there are similar issues relating to behaviour management facing all schools and teachers, our case study is in England, and so for the purposes of this study, our aims are addressing the requirements of the education system in England.

The English education system is broadly divided into the Primary sector, catering for children aged 5-11, and the Secondary sector, aimed at 11-19. Recently, there has been a great deal of change within the English education system with a new national curriculum for all age groups, and changes to the types of schools leading to the development of academies and free schools in both the Primary and Secondary sectors. The government's defining aim through these changes was to increase the opportunities for school autonomy and thereby develop a culture of selfimprovement [10]. As Hanushek, Link and Woessmann [11] suggest the thinking of this policy is that increasing school autonomy, when linked to with greater accountability, can result in raising standards. Such changes have also given schools the opportunity to work in collaboration to produce joint continuous professional development, though a consequence of this policy is that there is a loss of local authority support. This has meant that often that training of a comparable standard is no longer always possible across schools, and that schools now have either to develop their own professional development or buy into schemes or courses. Conversations with our own trainee teachers in schools indicate that some staff training days they have attended (where the school is closed to pupils and staff are expected to spend the time in developing their knowledge and skills through planned sessions) are didactic in approach, with little material available to them once the training day sessions are concluded. This project aims to produce an innovative approach to providing focussed high quality training for schools, produced in partnership with schools. The government are keen to encourage schools towards an evidence based practice agenda, and this project fits in well with this approach.

Behaviour management in English schools has always been a matter of much discussion, with many teachers claiming that behaviour is getting worse, though a recent report states that there is no conclusive evidence of this [12]. However, the UK Government's Office of Standards in Education, Children's Services and Skills (Ofsted) highlighted that in many classrooms there are still regular occurrences of low-level disruption, and that pupils in schools are potentially losing up to an hour's learning each day due to "low-level disruption" in classrooms [13]. Ofsted describe this low-level disruption as including such behaviours as: talking unnecessarily or chatting, calling out without permission, being slow to start work or follow instructions, showing a lack of respect for each other and staff, or not bringing the right equipment. Ofsted also comment that in their survey "too many school leaders underestimate the prevalence and negative impact of lowlevel disruptive behaviour" [13], adding that there are many teachers who now accept such disruption as being part of every lesson. This is not a purely an English problem, and the the findings of the recent international survey from the Programme for International Student Assessment (PISA), reveal that in most countries and economies, far too many students do not make the most of the learning opportunities available to them because they are not engaged with school and learning [14].

There is great number of books written to advise teachers on how to deal with behavioural issues in the classroom (see the works of Bill Rogers [17], Phil Beadle [18] and Sue Cowley [19]), and the UK Government also has provided further guidance [20]. However, all of these focus more on what the teacher should do, and do not look so much at the students perspectives. Recent surveys have investigated aspects of the pupils' perceptions of behaviour in their classes, and these show an interesting disparity between the views of head teachers and of the students. The PISA 2012 study highlights that whereas $7 \%$ of head teachers regarded that learning was hindered by disruption, $15 \%$ of students said they could not work well in their mathematics lessons because of disruption [14]. 
For behaviour management to be addressed effectively in schools there needs to be a clear school policy which is understood and followed by all staff [1]. Ofsted reported that only $25 \%$ of secondary school teachers surveyed felt that their school policy was applied consistently, whereas approximately $50 \%$ of primary school teachers agreed that this was the case [13]. In England, there is a legal requirement for schools to have policies for behaviour [15], and in the guidance provided by the UK Government, they state that the behaviour policies of schools should be clear, well understood by all staff (teaching and non-teaching), by parents and pupils, and that the policies are consistently applied across the school [16]. Furthermore, the guidance stresses that staff development and support with regards to behaviour management is important in developing an effective policy [16]. It is worth noting that in a survey of teachers in England undertaken by the National Foundation of Educational Research (NFER) in 2012, 60\% of those who participated stated that they had not received any professional development relating to managing pupil behaviour in the last 12 months, and of those who had, approximately $15 \%$ had received only informal support from their colleagues [21]. Ofsted's survey in 2014 reported more optimistic findings with only a third of all the teachers surveyed stating that they had not been given any training or professional development on dealing with behaviour. However, Ofsted added that of the staff who had received such professional development, approximately a third of secondary school teachers and a fifth of primary school teachers had found the training not very useful as it had not addressed the specific issues of low-level disruption [13].

As a consequence, this project aims to produce a framework for high quality training in addressing the issues of low-level disruptive behaviour from a student's perspective and linked in to a school behaviour policy.

\section{Project methodology}

Our case study school is a Primary School in a semi-rural setting in Essex, UK. It has approximately 270 children on the school roll, and has a history of taking Anglia Ruskin University trainee teachers on placement. The head teacher and the Board of Governors take seriously the UK Government aspirations of evidence based practice, and support staff who are keen to develop their research skills through a range of Continuing Professional Development (CPD) activities, including funding Masters and Doctoral studies, as well as having external links with universities. They have already collaborated with Anglia Ruskin University to capture 'best practice' writing throughout the school [22]; and with funding for staff development being transferred to school budgets, they have been keen to develop resources to assist both their own, but also other trainee teachers working in school classrooms across the East of England.
We worked with the school to agree the scope and parameters of our study, and went through both the school's and the university's risk and ethics approvals to ensure the safety and wellbeing of the children working on the project [23]. The school were happy with the focus on behaviour management, as they could see a real purpose for developing effective CPD in this area. They were particularly interested in the inclusion of $\mathrm{AR}$ within the design.

The end product will be a training course with AR triggers which will link to small video clips of 'critical incidents' in the classroom. These can then be discussed, and supported by further short videos of children and staff talking about the issues and possible ways of dealing with them, thereby engaging participants in a novel way of exploring a variety of issues related to classroom behaviour. Our technology of choice was AR as this links media (image/video/audio) to a scene viewed through the camera of a mobile device. Key features of the image or object are recorded by the application, which treats these like a URL or QR code to trigger linked media. The media can be presented on its own, but more typically it is laid over the scene in the camera image viewer to produce a composite, or augmented, view of reality. This technology has been identified as a successful instrument for education in a systematic literature by Shawky et al [24]. Furthermore, Johnson et al. state that 'Augmented reality can also help students learn by placing course content in rich contextual settings that more closely mirror real-world situations in which new knowledge can be applied' [2], and this very much reflected the aims of the project.

The data collection schema comprised:

- A co-design workshop with 8 children age 10 and three members of staff (see below),

- Filming day 1: work with year 6 children (age 10), during which the 'critical incidents' are staged,

- Filming day 2: film staff, pupils from other classes and school Governors, to gain other insights, comments, reactions, etc. to the critical incidents and behaviour management in general,

- Questionnaire evaluation: we have added three questions to the annual school/parent survey relating to behaviour management in schools so as to elicit some views of the parents.

Work is now underway to finalise the materials for the workshops, and will be the subject of a future evaluation paper.

\subsection{The co-design workshop approach}

During the children's workshop we followed a co-design approach [25] which helps to identify work-oriented design of computer artefacts in order to understand the requirements and steps; this prompts narration and design steps that children would work through preparing for 
filming. The co-design workshop consisted of collecting the information generated and proposed by the participants, observing how they created their ideas about classroom behaviour, and is a feature of design based research (DBR). DBR is a genre of research in which the iterative development of solutions to practical and complex educational problems also provides the context for empirical investigation, which yields theoretical understanding that can inform the work of others [26]. It emerged around a decade ago as an alternative paradigm which situates meaning in interventions offered in real-life settings [27].

\subsection{The co-design workshop with the children}

The children were selected for the workshop by their classroom teacher, and comprised four girls and four boys. We divided the children into two groups (each with two girls and two boys) and asked them to identify on cards the key aspects of classroom behaviour that they did not like. The children then ranked the replies in order, and each group selected the 'top' card to develop further ideas with. They were prompted to use storyboards to 'tell' their stories about poor behaviour, and to suggest ideas for dealing with this back in their own classroom context. It was noticeable that the staff working with the children were really surprised and bemused with the quality of thought and feedback. The children then developed a 'film script' storyboard to tell the story of the 'critical incident' they had identified, and worked together drawing narratives and rapidly decided, without adult intervention, that they would writing a script for the potential actors who would be filmed telling the story of the incident.

The themes the children developed were taken back into the classroom, and developed through the English and Drama curricula. The school then invited us into their classroom to film the 'critical incidents'. Key themes will be analysed and summarised, and exemplars will be hosted through the project website, ready for dissemination and feedback at conferences, workshops and talks; after which the final materials will be produced and reviewed in the pilot for the CPD workshop with the teachers.

\subsection{A constructivist approach to the CPD workshops}

To move the co-design workshop findings into a useful tool that would enable autonomous individual learning mediated by technology [28], and staff development where trainee teachers work together using a collaborative learning framework, the team decided to host materials on a website. This website is constructed with school based materials developed in conjunction with the teachers and the children from the school. This rich resource offers the basis for interactive study to develop content knowledge, and the materials are available to form the basis of CPD workshops which can be customised and so provide a unique learning context directly relevant to the workshop participants.

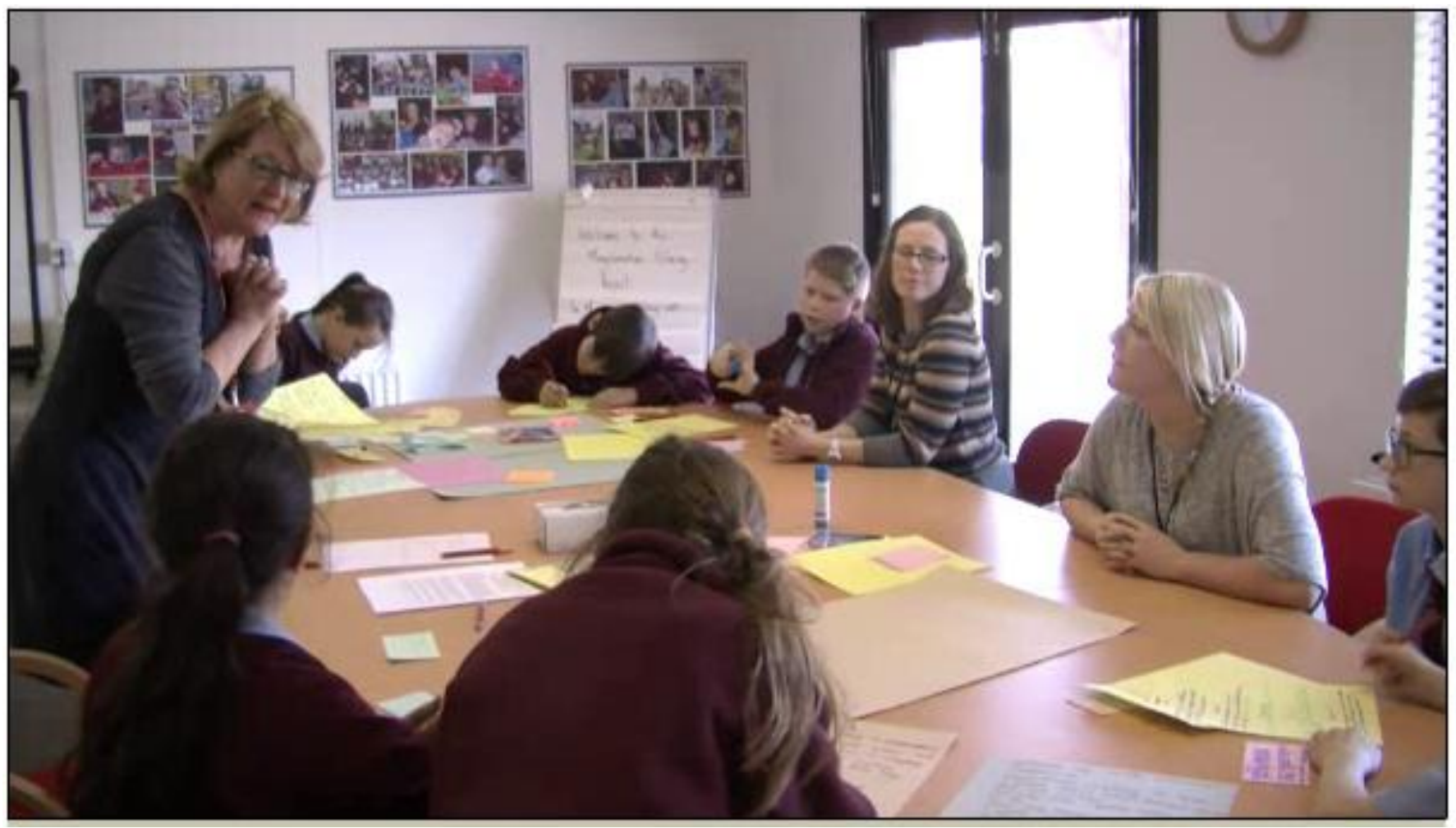

Figure 1. The co-design workshop in action 
Table 1. The summary of project activities

\begin{tabular}{|c|c|}
\hline Activities in school & Activities at University \\
\hline \multicolumn{2}{|c|}{$\begin{array}{l}\text { Initial meeting with key staff: } \\
\text { Governors, Head teacher, classroom teachers, researchers }\end{array}$} \\
\hline $\begin{array}{l}\text { School agree to collaborate: } \\
\text { School obtains necessary consent forms from parents and } \\
\text { children, and agreement from staff to be filmed }\end{array}$ & Full ethical approval processes undertaken \\
\hline \multicolumn{2}{|c|}{$\begin{array}{l}\text { Co-design Workshop: } \\
8 \text { children, } 4 \text { boys and } 4 \text { girls plus two classroom teacher and the researchers }\end{array}$} \\
\hline & $\begin{array}{l}\text { Preparation of materials for workshop } \\
\text { Literature review }\end{array}$ \\
\hline $\begin{array}{l}\text { Filming of staff: } \\
\text { Staff who have agreed are filmed answering these four } \\
\text { questions: } \\
\text { - What behaviour do you find most annoying? } \\
\text { - How does disruption in the class make you feel? } \\
\text { - What is the best way of tackling disruption in class? } \\
\text { - Describe in your own words a good learning environment }\end{array}$ & $\begin{array}{l}\text { Initial themes: } \\
\text { - Low level disruption is the key issue } \\
\text { - A degree of frustration with having to repeat the same } \\
\text { instructions to certain children } \\
\text { - Staff were able to articulate effective ways they were able } \\
\text { to encourage good behaviour } \\
\text { - Staff were very consistent in their views and these aligned } \\
\text { to the school policy document }\end{array}$ \\
\hline
\end{tabular}

Filming day with full classroom of children:

30 children take part in filming 'issues' they have prepared - the children have researched, and written scripts and briefing plans for their group 'film'

\begin{tabular}{r|l}
\hline \multicolumn{1}{c}{$\begin{array}{l}\text { Preparation of interactive website: } \\
\text { Conference preparation }\end{array}$} \\
\hline \multicolumn{2}{c}{ 'Calmer Classroom' website developed between the school and university } \\
\hline School act as 'critical friends' and review materials & Feed into site development process \\
\hline
\end{tabular}

The design of the CPD workshops is envisaged to use AR triggers linked to the website-based short video clips of the 'critical incidents' in the classroom. The participants can then discuss in small groups the issues and the best ways to approach the incidents. A series of 'games/exploration/play' type challenges linked to each of the scenarios are included to stimulate or develop further discussion. This design is largely based on a social constructivist approach to developing understanding, building on Vygotsky's concepts of the Zone of Proximal Development, where the learner is more actively involved in constructing new meaning in a collaborative enterprise [29].

Twomey Fosnot describes the constructivist approach as a "process of struggling with the conflict between existing personal models and new insights", emphasising that meaning-making can be furthered by collaborative negotiation, discourse and debates in communities of practice [30]. The opportunity for the participants to be able to discuss and compare ideas will lead to a deeper awareness of the issues, especially when linked to the other resources relating to issues such as school policies and the importance of consistency.

Opfer and Peder outline that too often CPD for teachers in England consists of passive sessions which are decontextualised and rarely involve any collaboration with colleagues [31]. They suggest that CPD which addresses particular issues within the school and which allows colleagues to work together so as to generate new information or understanding are the most valued forms of training. Opfer and Peder add that the best CPD will include collaborative and research-informed approaches, and involve active learning strategies which are pertinent to classroom practice [31]. This view is supported by 
Whitehouse who states that effective CPD is primarily driven by identified learning needs, based in the classroom, and is collaborative [32]. These features have been included in the design of this project.

\section{The school as 'critical friends'}

In order to continue to develop the project, an Augmented Reality CPD session was organised at our host school so that they could act as a 'critical friend'. A total of eight staff, together with the head teacher, spent two hours working through materials the research team had developed. So as to familiarise the staff with the basics of AR and how the Aurasma app might be used, the session was based around 'my favourite children's book'. Each staff member brought along a book that they enjoyed reading to the children in their class.

The session began with a review of the project, and a basic overview of what AR was, the affordances for commercial use and also for co-creation use in the classroom - such a development in the role of AR in education has been documented by Bower et al. [33]. As the session progressed, it was soon evident that some staff, who clearly were initially very sceptical about the uses of technology, were transformed as they worked through their own examples.

All the workshop participants successfully created their own artefacts, and then we were able to progress the discussion by suggesting a number of ways in which this type of technology might be embedded across the whole school by the creation of an AR 'channel'. The staff were quick to offer their own suggestions as within the short time of the training session, they began to experiment with their ideas. Some of the suggestions included innovative ideas, such as using AR to produce a form of talking book using the pages from the book as the triggers, or demonstrating how to carry out particular exercises for Physical Education sessions which would save the teacher repeating explanations.

The final part of the workshop officially launched the 'Calmer Classroom' website (http://tinyurl.com/za23nef), which features the video clips arising from the filming which had taken place in the school earlier in the year. The staff who had not been involved with the filming were overwhelmingly positive about the website, and extremely interested in the co-design process that had led to the body of work. The video clips were a clear favourite, and they particularly liked the way in which there was a 'games/ exploration/play' type challenge to further embed the knowledge about children's behaviour in the games under each category identified.

Reflecting on the project plans, we had anticipated that the 'Calmer Classroom' would be of use to staff in terms of developing their own skills and subject knowledge in this area. We were therefore surprised by some of the teachers' suggestion, as they would be keen to use extracts from the website for other purposes, for example in stimulating discussions regarding the impact of poor behaviour with the children in their own classes, or even for use at parents' evenings.

\section{Emerging themes}

A number of themes have emerged from this study, and they can be grouped into two: themes relating to behaviour management, and themes relating to the use of the technologies. With respect to behaviour management, our initial findings have identified a significant 'gap' in the literature on classroom behaviour in UK schools, in that much of what has been written focusses on the teacher's perspective and little is written about the children's perspective. Consequently, some of the children's responses to the co-design workshop were a surprise. Whereas we would have expected the children to have focussed on the major disruptions in a classroom, in line with the usual concerns of trainee and newly qualified teachers [34], the children expressed most frustration with low level misbehaviour. This compares with the findings from the recent PISA study where students commented on their frustrations regarding other students who do not listen to what the teacher says, or when there is noise and disorder in the class, and the students are slow to settle to their work [14]. A further interesting point was that the children initially felt that the punishments should be much more severe than we would have expected. They then softened their responses on discussion with the teachers about why the teachers responded in the ways that they did. This would suggest that it is important that when approaching behaviour management the views of both the children and the adults are included. The opportunities afforded by these videos will be helpful in stimulating discussions among both teachers and pupils.

A number of themes relating to the use of $A R$ as a technology to support CPD also have begun to emerge. One aspect is the interest that AR can engender in both staff and pupils, and they both became very eager to explore the use of AR, not just for this project, but in other aspects of the learning and teaching in the school. The teachers, in particular, could see it as a way of embedding technology in the curriculum for the children, as well as using to help train teachers in the future. An associated important consideration, bearing in mind the initial reticence of the staff to use AR, is the reality of using such technology in the complex classroom context. Cuendet et al. [35] discuss the need to ensure that technology satisfies certain constraints in any learning environment, but above all in 'real-world' busy classrooms. They describe five key design principles for a learning environment:

- integration of the technology into the classroom activities so as to be a way of enhancing existing approaches; 
- empowerment of the teacher to encourage and support the learners to reflect on their learning and their progress;

- awareness of the teacher on the progress of the learners and so enable a means of monitoring this;

- flexibility of the learning environment so as to enable the teacher to manage the varying levels of skill of the learners;

- minimalism so as to keep the task as focussed as possible and reduce the potential for off-task interruptions.

Each of these considerations impact on the ease with which the technology can be used within the lesson so as to engender cognitive, deep learning [35]. The use of AR in the classroom needs to be measured against these; one pitfall that can easily arise with the introduction of any technology into teaching is that because of the novelty factor, any real pedagogical merit is forgotten or even ignored.

\section{Conclusions}

Our initial findings have identified a significant 'gap' in the literature on classroom behaviour in UK schools, and it implies that there is a greater need to incorporate both the adult and children's voices in any development of training in such issues. Messiou [36] has previously stated that children's voices should be taken into consideration so as to develop inclusive practices, and it is evident from our study that there is much to be gained in this. Clearly, there is also potentially a big interest in schools for the use of interactive technologies, and both staff and pupils are excited by the prospect. The school 'film day' materials are currently being analysed, together with the staff and children's viewpoints. The initial film clips comprising children's stories and our materials will be available to share later this year, and these will be developed into workshop materials. These will then provide a more authentic learning experience through the use of AR and the incorporation of 'real' user-generated content [37].

\section{Acknowledgements.}

The authors would like to express their thanks to the all the staff of Maylandsea Primary School, especially for participating on project: Dr Rudman (Head Teacher), Mrs McCann (Deputy Head Teacher), Mr Kirsh (Senior Teacher), Mrs Park (Senior Teacher), Mrs Dobson (Teacher), Mrs Crowhurst (Teacher), and Mrs Foster (Teacher). We would like to thank all wonderful pupils at Maylandsea School. We also would like to acknowledge Anglia Learning and Teaching for funding our learning and teaching project.

\section{References}

[1] Haydn, T. (2007) Managing Pupil Behaviour. Improving the classroom atmosphere. 2nd ed. (Routledge, London)

[2] Johnson, L., AdAms Becker, S., Cummins, M., Estrada, V., Freeman, A., and Hall, C. (2016) NMC Horizon Report: 2016 Higher Education Edition. (Austin, Texas: The New Media Consortium)

[3] Bloxham, J. (2013) Pedagogical arguments for Augmented Reality as an educational tool. (JISC, RSC blog) [online] http://jiscrsc.jiscinvolve.org/wp/2013/05/augmentedreality-education/

[4] OFCOM (2013) Communications Market Report 2013. [online]

http://stakeholders.ofcom.org.uk/binaries/research/cmr/cmr 13/2013_UK_CMR.pdf

[5] CDW-G (2011) The 21st century classroom REPORT (CDW Govt. [online] http://www.edtechmagazine.com/k12/sites/edtechmagazine .com.k12/files/rg_21stcent_k12_031011.pdf

[6] Bradley, C. and Holley, D. (2011) Empirical Research into students' mobile phones and their use for learning, International Journal of Mobile and Blended Learning, 3(4): $38-53$

[7] FINK, S. (2012) Simple things done well, making practical progress on digital engagement and inclusion. [online] http://www.policyexchange.org.uk/images/publications/si mple\%20things\%20done\%20well.pdf

[8] VUFORIA (2014) Vuforia developer portal. [online] https://developer.vuforia.com/

[9] Aurasma (2014) Aurasma, home page. [online] http://www.aurasma.com/

[10] SANDALS, L. and BRYANT, B. (2014) The evolving education system in England: a "temperature check". (DFE-RR359) (London: DfE)

[11] HanusheK, E., Link, S. and Woessmann, S. (2011) Does school autonomy make sense everywhere? Panel estimates from PISA, IZA Discussion Papers No.6185.

[12] DFE (2012) Pupil behaviour in schools in England. (DFERR218) (London: DfE)

[13] OFSTED (2014) Below the radar: low-level disruption in the country's classrooms. (Report No. 140157) (Manchester: Ofsted)

[14] OECD (2013) PISA 2012 Results: Ready to Learn: Students' Engagement, Drive and Self-Beliefs (Volume III). (OECD, www.oecd.org/pisa/keyfindings/pisa-2012-results-volumeiii.htm)

[15] Education and Inspection Act 2006 (Section 89). (London: HMSO)

[16] DFE (2014) Behaviour and discipline in schools. Advice for headteachers and school staff. (DFE-00023-2014) (London: DfE)

[17] Rogers, B. (1998) You Know the Fair Rule, 2nd ed. (London: Pitman Publishing)

[18] Beadle, P. and MurPhy, J. (2013) Why are you shouting at us? The dos and don 'ts of behaviour management. (London: Bloomsbury)

[19] Cowley, S. (2014) Getting the Buggers to Behave, 5th ed. (London: Bloomsbury)

[20] TAYloR, C. (2011) Getting the Simple Things Right: Charlie Taylor's behaviour checklist (London: DfE)

[21] DFE (2012) NFER Teacher Voice Omnibus February 2012 survey: pupil behavior. (DFE-RR219) (London: DfE) 
[22] Feist, A. and Holley, D. (2013) The 9/10 project: working towards getting $9 / 10$ students to recommend us to a friend. Anglia Ruskin University Networks 16:31-36. http://www.lta.anglia.ac.uk/networkIssues.php/ENGAGE13th-Annual-Learning-and-Teaching-Conference-2012Learning-and-Teaching-Project-Reports-4/

[23] BERA (2011) Ethical Guidelines for Educational Research. (London: British Educational Research Association)

[24] Shawky, D., Said, T., Badawi, A. and Hozayin, R. (2014) Affordances of computer-supported collaborative learning platforms: A systematic review. In Proceedings of 2014 International Conference on Interactive Collaborative Learning, Dubai, December 2014 (Red Hook: IEEE), 633651

[25] EHn, P. (1988): Work-oriented design of computer artifacts, vol. 78. (Stockholm: Arbetslivscentrum)

[26] McKenney, S. and ReEves, T. (2012) Conducting Educational Design Research. (New York; Routledge)

[27] MoR, Y. and WINTER, N. (2008) Participatory design in open education: a workshop model for developing a pattern language. Journal of Interactive Media in Education, 2008(1):12

[28] CoOK, J. (2010) Mobile phones as mediating tools within augmented contexts for development. International Journal of Mobile and Blended Learning, 2(3):1-12

[29] Hean, S., Craddock, D. and O'Halloran, C.: Learning theories and interprofessional education: a user's guide. Learning in Health \& Social Care, 8(4): 250-262
[30] Twomey Fosnot, C. (2005) Preface. In Twomey Fosnot, C. [ed.], Constructivism: Theory, Perspectives, and Practice. 2nd ed. (New York: Teachers College Press)

[31] Opfer, V.D. and PedDER, D. (2010) Benefits, status and effectiveness of Continuous Professional Development for teachers in England. Curriculum Journal, 21(4): 413-431

[32] Whitehouse, C. (2011) Effective continuing professional development for teachers. (Manchester: AQA Centre for Education Research and Policy)

[33] Bower, M., Howe, C., McCredie, N., Robinson, A. and Grover, D. (2014) Augmented Reality in education - cases, places, and potentials. Educational Media International, 51(1): $1-15$

[34] BRomfiELD, C. (2006) PGCE Secondary Trainee Teachers \& Effective Behaviour Management: an evaluation and commentary. Support for Learning, 21(4): 188-193

[35] Cuendet, S., Bonnard, Q., Do-Lenh, S. and DillenbourG, P. (2013) Designing augmented reality for the classroom. Computers and Education, 68:557-569

[36] Messiou, K. (2004) Marginalisation in primary schools: listening to children's voices. In WEARMOUTH, J., Richmond, R.C., GlynN, T. and BERRYMAn, M. [eds], Understanding Pupil Behaviour in Schools: A diversity of approaches. (London: David Fulton Publishers), ch 3.

[37] BoyLE, T. (2008) Dreams and responsibilities: learning and the new technologies, In Allen, M. [ed.] Michael Allen's 2008 e-Learning Annual (San Francisco:. JB Pfeiffer), section 3 . 